\title{
Screening of melon genotypes identifies gummy stem blight resistance associated with $G s b 1$ resistant loci
}

\author{
Md Zahid Hassan - Arif Hasan Khan Robin - Md Abdur Rahim - Sathishkumar Natarajan • Hoy-Taek Kim • \\ Jong-In Park • IIl-Sup Nou
}

Received: 14 September 2018 / Revised: 14 September 2018 / Accepted: 20 September 2018

(c) Korean Society for Plant Biotechnology

\begin{abstract}
Gummy stem blight (GSB) is one of the most destructive and economically important, soil borne diseases of melon caused by the ascomycete fungus, Didymella bryoniae throughout the world. In Korea, however, no GSB resistant genotype has been reported yet. The study aimed to identify GSB resistant melon germplasm. We screened a total of 60 genotypes including 16 lines and 44 melon cultivars collected from USA and Korea. Among the 16 melon lines, four lines including 'PI482399', 'PI140471', 'PI136170' and 'PI420145', and two Korean cultivars viz. 'Asia Papaya' and 'Supra' showed complete resistance. We were aware that both genotypic and environmental variations could influence the phenotypic screening of resistance and susceptibility. We therefore, further assessed all genotypes using 20 SSR markers. The SSR marker 'CMCT505' linked to Gsb1 in chromosome 1 perfectly grouped resistant and susceptible lines indicating that resistance is probably due to the presence of Gsbl gene. Cloning and sequencing of resistant and susceptible Gsbl amplicons showed that there were 32-bp deletions in resistant line and 39-bp deletions in resistant cultivar compared to susceptible one. Thus, the resistant melon lines and cultivars identified in
\end{abstract}

M. Z. Hassan • A. H. Khan Robin · M. A. Rahim · S. Natarajan · H.-T. Kim $(\bowtie) \cdot$ J.-I. Park $\cdot$ I.-S. Nou $(\bowtie)$ Department of Horticulture, Sunchon National University, 255 Jungang-ro, Suncheon, Jeonnam 57922, Republic of Korea e-mail: htkim@sunchon.ac.kr,nis@sunchon.ac.kr

M. Z. Hassan

Department of Agronomy, Patuakhali Science and Technology University, Dumki, Patuakhali 8602, Bangladesh

M. A. Rahim

Department of Genetics and Plant Breeding, Sher-e-Bangla Agricultural University, Dhaka-1207, Bangladesh

H.-T. Kim

University-Industry Cooperation Foundation, Suncheon National University, 255 Jungang-ro, Suncheon, Jeonnam 57922, Republic of Korea this study could be recommended for the melon breeding program. Furthermore, the SSR marker 'CMCT505' which is tightly linked with Gsbl could be used for molecular screening of melon germplasm.

Keywords Gummy stem blight, Didymella bryoniae, Melon, SSR markers, Screening

\section{Introduction}

Gummy stem blight (GSB) is one of the destructive soil borne diseases of melon caused by the ascomycete fungus, Didymella bryoniae (Auersw.) Rehm resulting significant economic loses (Crosby et al. 2002; Wako et al. 2002; Frantz and Jahn, 2004). The disease symptoms initially comprise with water-soaked lesions that later spread and produce necrotic lesions on both leaves and hypocotyls resulting formation of stem cankers in cortical tissue that consequently produces brown gummy exudate (Frantz and Jahn, 2004). During severe infections, these lesions continue to expand, finally girdling the stem leading to wilting and death of the plant (Sitterly and Keinath, 1996). The pathogen also rigorously attacks the other genera of the Cucurbitaceae family around the world and causes substantial loses in the yield and quality (StAmand and Wehner, 1991; Zitter and Kyle, 1992; Keinathet al. 1995; Gusmini and Wehner, 2002). Though, chemical control has been used to manage GSB, its frequent use poses adverse effect on the environment (Joseph et al. 2009). Crop rotations were often found partially efficacious, because of airborne inoculum coming in from other areas that initiate the incipient infections (Tullu et al. 2002). Consequently, the utilization of resistant cultivars can be the most economically and environmentally sustainable way of GSB disease management. GSB resistance in melon have been reported by a number 
of sources have been reported GSB resistance in melon, however, the most GSB-resistant melon varieties and breeding lines released to date have been developed from an USDA-developed resistant accession, 'PI140471' (McGrath et al. 1993; Norton and Cosper, 1989), and have failed to offer satisfactory levels of resistance (Zhang et al. 1997). But conflicting data exists for that USDA-developed melon accession. For example, plant introduction 'PI140471' was reported to be ineffective against a Japanese isolate of D. bryoniae (Sakata et al. 2000). The melon accessions 'PI482398', 'PI157082' and 'PI511890' were reported to carry the monogenic dominant gene for GSB resistance, whereas 'PI482399' was monogenic recessive (Frantz and Jahn, 2004). Among the three accessions bearing monogenic dominant genes 'PI482398' was reported to be a highly resistant against $D$. bryoniae (Zhang et al. 1997 and Wang et al. 2012). On the other hand, Joseph et al. (2007) reported monogenic recessive gene bearing 'PI482399' as a susceptible genotype to GSB in their study. However, no D. bryoniae race has been reported to date. Therefore, exploration of novel sources GSB resistance is apparent which could be useful in melon-engendered areas where existing sources of resistance are not efficacious (Wolukau et al. 2007).

Screening of resistant germplasm based on phenotypes is not an effective means due to the influence of environmental factors. Hence, the use of molecular markers linked to resistance could be an essential step forward for both marker assisted selection (MAS) and map based cloning (Wolukau et al. 2009). In several genetic applications like genetic diversity, genetic mapping and fingerprinting, microsatellite or simple sequence repeats (SSR) markers were frequently used ( $\mathrm{Lv}$ et al. 2012; Li et al. 2013). For reproducibility, co-dominance and multiallelism, SSR markers are expected to continue to be used in various genetic applications such as MAS, genetic diversity and gene mapping (Zhu et al. 2016). Therefore, this study endeavored to screen and evaluate the melon germplasm resistance to GSB with the combination of bioassay as well as SSR markers.

\section{Materials and Methods}

Plant materials and growing condition

A total of 60 melon genotypes, 16 lines, and 44 commercial cultivars, were used in this experiment (Table 1). Among these, 15 melon lines including control resistant melon line 'PI482398' and control susceptible line 'Honeydew Green- flesh' were collected from, Department of Plant Breeding and Genetics, Cornell University and USDA, ARS, USA. The resistance reaction of these germplasm was re-assessed in this study to confirm the control resistant and susceptible lines would be consistently resistant or susceptible, respectively, against tested fungal isolate. The melon line SCNU1154 was collected from Department of Horticulture, Sunchon National University (SCNU). Forty-four melon commercial cultivars were collected from Korean Genebank, National Agrobiodiversity Center. Leaves of 12 other melon inbred lines, namely R36, R37, R40, R51, R60, S1, S2, S3, S4, S6, S6 and S50 were collected from Daeyeon Breeding Company, Republic of Korea, which were used for screening 38 SSR markers. Seedlings were developed in 32-celled trays containing artificial soil mix in a controlled plant growth chamber at $24 \pm 2^{\circ} \mathrm{C}, 16 \mathrm{~h}$ days, and light intensity $400 \mu \mathrm{mol} \mathrm{m} \mathrm{m}^{-2} \mathrm{~s}^{-1}$ at bench level. In the entire screening tests, the melon lines 'PI482398' and 'Honeydew Greenflesh' were used as a resistant and susceptible control, respectively with a view to compare the disease reactions of gummy stem blight disease symptoms on the inoculated leaves.

Fungal isolate and inoculum preparation

D. bryoniae fungal isolate no. 12-003 was collected from National Institute of Horticultural and Herbal Science, Republic of Korea. The fungus was cultured on petri plates having $15 \mathrm{~mL}$ potato dextrose agar (potato infusion $4 \mathrm{~g} \mathrm{~L}^{-1}$, dextrose $20 \mathrm{~g} \mathrm{~L}^{-1}$, agar $15 \mathrm{~g} \mathrm{~L}^{-1}$ ). Inoculated plates were incubated at $24 \pm 2{ }^{\circ} \mathrm{C}$ under alternating periods of $12 \mathrm{~h}$ fluorescent light (40 to $90 \mu \mathrm{mol} \cdot \mathrm{m}^{-2} \cdot \mathrm{sec}^{-1}$ PPFD) and $12 \mathrm{~h}$ darkness for 2 to 3 weeks until sporulating pycnidia formed. A spore suspension was prepared by inundating the culture plates with 5 to $10 \mathrm{~mL}$ of sterile, distilled water having Tween-20 (20 dropsL $\left.\mathrm{L}^{-1}\right)$ that helps to dislodge the spore from mycelia and pycnidia, and by gently scraping the surface of the agar using an L-shaped rubber spreader. The liquid suspension from each plate was sieved through a fourlayered Mira-cloth (EMD Millipore Corporation, USA) to eliminate mycelia, pycnidia and dislodged agar. Spore concentration was adjusted with a hemocytometer and light microscope (Leica DM750, Leica, Switzerland) to a concentration of $5 \times 10^{5}$ sporesml $^{-1}$ by adding deionized water.

Inoculation of plants

Plants were inoculated at the fourth true leaves stage. The third leaf was cut keeping the long petiole where the youngest leaf was the reference. The petri dishes $(90 \times 15 \mathrm{~mm}$, SPL 
Table 1 List of melon genotypes used for genotypic and phenotypic assay for resistance to Didymella bryoniae

\begin{tabular}{|c|c|c|c|c|c|}
\hline Sl. no. & Genotype & Seed source & Sl. no. & Genotype & Seed source \\
\hline 1 & PI482398 & USDA & 31 & JeonnamMelli & KGNAC \\
\hline 2 & PI482399 & CU, USA & 32 & Sweet Lady & KGNAC \\
\hline 3 & Cornell ZPPM 339 (ZM) & CU, USA & 33 & Earls Elite & KGNAC \\
\hline 4 & Honeydew Greenflesh (HD) & CU, USA & 34 & Earls Taitan & KGNAC \\
\hline 5 & PI140471 & USDA, USA & 35 & Kings Daebak & KGNAC \\
\hline 6 & PI157082 & USDA, USA & 36 & Earls Mountain PMR & KGNAC \\
\hline 7 & PI136170 & USDA, USA & 37 & Kingdom & KGNAC \\
\hline 8 & PI420145 & USDA, USA & 38 & Earls Grand & KGNAC \\
\hline 9 & MR1 & USDA, USA & 39 & SS-402 & KGNAC \\
\hline 10 & PMR5 & USDA, USA & 40 & Muskmelon SS Anup & KGNAC \\
\hline 11 & PMR45 & USDA, USA & 41 & Asulan PMR & KGNAC \\
\hline 12 & WMR29 & USDA, USA & 42 & Ropey King & KGNAC \\
\hline 13 & Edisto47 & USDA, USA & 43 & Napoyon & KGNAC \\
\hline 14 & PI414723 & USDA, USA & 44 & Baldo & KGNAC \\
\hline 15 & PI124112 & USDA, USA & 45 & VCR-601 & KGNAC \\
\hline 16 & SCNU1154 & SCNU, Korea & 46 & Earls ok & KGNAC \\
\hline 17 & Charantais & KGNAC & 47 & White Honey & KGNAC \\
\hline 18 & Ananas & KGNAC & 48 & Giant Iryesaback & KGNAC \\
\hline 19 & Alpeon & KGNAC & 49 & Jochun 26 & KGNAC \\
\hline 20 & Dakkijeogyuk & KGNAC & 50 & Valencia Early-rochet & KGNAC \\
\hline 21 & Earls Red & KGNAC & 51 & Asia Papaya & KGNAC \\
\hline 22 & Earls top one & KGNAC & 52 & Eunpa 3 & KGNAC \\
\hline 23 & Ipchumdaegil & KGNAC & 53 & ME4759 & KGNAC \\
\hline 24 & Captain & KGNAC & 54 & Eunpa fall \& Winter melon & KGNAC \\
\hline 25 & Darle Spring \& Fall & KGNAC & 55 & Happiness & KGNAC \\
\hline 26 & Asia Summer & KGNAC & 56 & Sunflower & KGNAC \\
\hline 27 & Raina & KGNAC & 57 & Vivadi & KGNAC \\
\hline 28 & Pestar & KGNAC & 58 & Snow White Melon & KGNAC \\
\hline 29 & Earls Focus & KGNAC & 59 & Supra & KGNAC \\
\hline 30 & Earls Grand Prix & KGNAC & 60 & Chungja & KGNAC \\
\hline
\end{tabular}

Melon lines (1-16) and melon commercial cultivars (17-60), CU = Cornell University, United States of America and USDA = United States Department of Agriculture, SCNU = Sunchon National Unversity, Republic of Korea, KGNAC = Korean Genebank, National Agrobiodiversity Center

Life Sciences Co. Ltd, Korea) were arranged and made a hole at the border region of the cover of each petri dish. About $20 \mathrm{~mL}$ of distilled water was added to each petri dish. The spore suspension was applied on the leaf surface near to runoff using a hand-pumped spray bottle. Immediately after inoculation, leaves were kept on the petri dish facing the upper surface of the leaf to air and the lower surface in touch of water so that leaf can take enough moisture from petri dish for disease development. The leaf petioles were inserted through the hole created on the cover of the petri dish. The petri dishes with inoculated leaves were placed in a plastic tray box and properly sealed to maintain $90 \sim 100 \%$ relative humidity inside the box. To spread of the inoculum and encourage uniform disease development the leaves were watered three days consecutively after inoculation.

\section{Disease ratings}

Symptoms began to visible on the leaves at seven days after inoculation. The final scoring was done at 14 days after inoculation when symptoms were much prominent. 

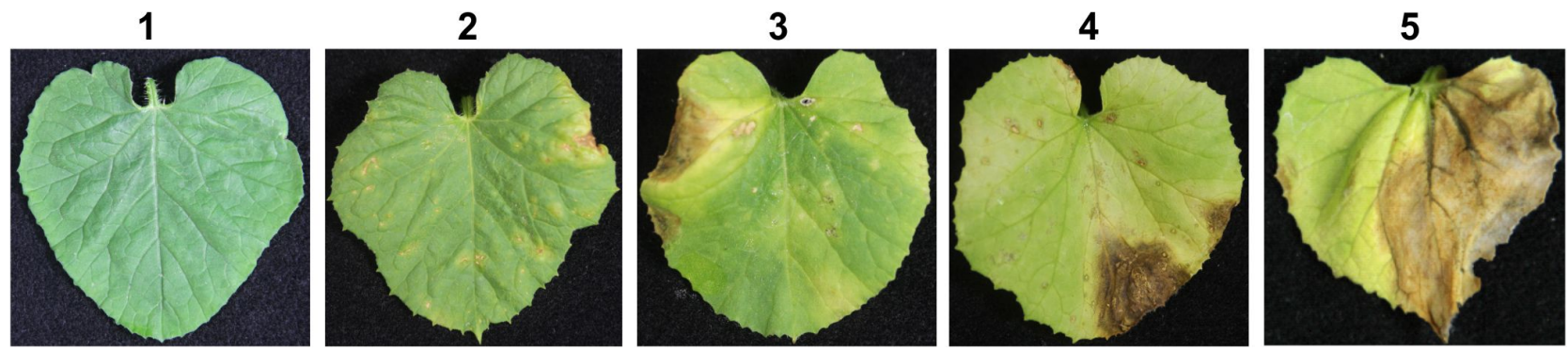

Fig. 1 Scale of phenotypic categorization according to the reaction of melon leaves infected with Didymella bryoniae. Leaves were rated according to the following scales: $1,0 \%$ leaf area affected; 2, 1-10\% leaf area affected; 3, 11-30\% leaf area affected; $4,31-50 \%$ leaf area affected; 5, 51-100\%

The rating system was done following Zhang et al. (1997) with modifications, to distinguish resistant and susceptible plants. During screening, each leaf was given a rating, and that was averaged across three replications within a genotype to determine a mean rating for each genotype. Leaves were rated according to the following scales: $1=0 \%$ of leaf area affected, $2=1-10 \%$ leaf areas affected, $3=11-30 \%$ leaf area affected, $4=31-50 \%$ leaf area affected, $5=51^{-}$ $100 \%$ (Fig. 1). Percent infected area was measured by eye estimation as a ratio between infected areas by total leaf area and multiplied by 100 .

\section{Analysis of SSR markers}

Thirty-eight SSR markers which were initially selected from melon (Liu et al. 2009; Wang et al. 2012) and cucumber genome (Ren et al. 2009) linked to GSB resistance. These 38 markers were amplified using 12 melon lines (Table 2). A total of 20 markers out of 38 amplified genomic complements of melon. The selected 20 markers were used to analyze the status GSB resistance in melon genotypes.

\section{Genomic DNA isolation and marker screening}

Young leaf samples were collected for DNA isolation from the individually tagged melon plants grown in a growth chamber at three weeks after germination. Genomic DNA of all melon genotypes was extracted using the DNeasy Plant Mini Kit (QIAGEN, Hidden, Germany) as per manufacturer's instructions. The quality of extracted DNA was determined by a Nanodrop ND-1000 spectrophotometer (NanoDrop, Wilmington, DE, USA).The genomic DNA of 16 melon lines and 44 cultivars were screened using 20 amplified SSR markers.

PCR amplification and electrophoresis
The PCR reaction was set up to a final volume of $20 \mu \mathrm{l}$ containing $1.0 \mu \mathrm{l}$ of template DNA of $50 \mathrm{ng}$ concentration, $1.0 \mu \mathrm{l}$ each of forward and reverse primers of $10 \mathrm{pmol}$ concentration, $10 \mu \mathrm{l}$ of $2 \mathrm{X}$ Prime Taq Premix (GENET BIO) and $7 \mu \mathrm{l}$ distilled water. The PCR program comprised an initial denaturing at $94^{\circ} \mathrm{C}$ for $5 \mathrm{~min}$ followed by 30 cycles of $94^{\circ} \mathrm{C}$ for $30 \mathrm{~s}, 58^{\circ} \mathrm{C}$ for $30 \mathrm{~s}$, and at $72^{\circ} \mathrm{C}$ for 1 minute with a final extension of $72^{\circ} \mathrm{C}$ for 7 minutes. The PCR products were separated on $1.5 \%$ denaturing agarose gels with a $100 \mathrm{bp}$ ladder prepared in TAE buffer and visualized by staining with ethidium bromide $(0.5 \mu \mathrm{g} / \mathrm{ml})$ in a gel documentation system.

\section{Cloning and sequencing of marker amplicons}

Markers with high adaptability were selected for cloning and sequencing. Resistant and susceptible lines were cloned and sequenced using three amplified markers CMCT505, SSR02460, SSR13251 to find out genetic variants between resistant and susceptible genotypes. The cloned sequences were compared with the published sequences of $C$. melo to confirm whether the primers correctly amplified the target sequences or not. To clone the marker sequence, the PCR protocol as stated above was followed to amplify resistant and susceptible lines. The amplified DNA fragments were purified using Promega DNA Purification kit (Promega, Madison, WI, USA) according to the manufacturer's instructions. Cloning was performed using the TOPO TA cloning kit (Invitrogen, Carlsbad, CA, USA) following the instructions provided by the manufacturer, but the reaction volumes were halved. The cloned amplicons were sequenced by the universal primers M13F and M13RpUC using the ABI3730XL sequencer (Macrogen Co., Seoul, Republic of Korea). Each forward and reverse sequence of each of the melon resistant and susceptible line was repeated five times to eliminate all ambiguities. The marker sequences between resistant and susceptible lines were also compared using 
Table 2 List of SSR markers linked to gummy stem blight resistant (GSB) gene and specifications

\begin{tabular}{|c|c|c|c|c|}
\hline S1. No. & SSR name & Forward sequence & Reverse sequence & Length (bp) \\
\hline 1 & CMCT505 & GACAGTAATCACCTCATCAAC & GGGAATGTAAATTGGATATG & 210 \\
\hline 2 & CMGA104 & TTCTGGGTTTTGCCGATTT & AATTCCGTATTCAACTCTCC & $120-250$ \\
\hline 3 & CMAT141 & AAGCACACCACCACCCGTAA & GTGAATGGTATGTTATCCTTG & $120-250$ \\
\hline 4 & CMTA170a & TTAAATCCCAAAGACATGGCG & AGACGAAGGACGGTTAGCTTT & $120-250$ \\
\hline 5 & CMCT160a $+b$ & GTCTCTCTCССТTATCTTCCA & GATGGTGCCTTAGTTGTTCCG & $120-250$ \\
\hline 6 & SSR02697 & TGCTAACCCAACCAAACAAA & CTGCCATTTCAAGCTATGGG & 219 \\
\hline 7 & SSR26165 & TCTTTTGTTGGTGAAAATTGAAA & CCTTCTCATGTGTATTGTCTTTTG & 148 \\
\hline 8 & SSR06347 & TATGGGCCCAGTCCATCATA & CССАAАТCTGACСТTСССТT & 212 \\
\hline 9 & SSR04534 & GGTTCAAACCCCCTCAACTT & GGGGGTTGGGAGACAGTTAT & 151 \\
\hline 10 & SSR17406 & GAGCCATCCATCAGAGAGAGA & ACCCACAAGCTTCAGAGGTC & 174 \\
\hline 11 & SSR04649 & TTTGAAATTGATGACATCCCA & ACATGGAGGAAGACAGGCAC & 195 \\
\hline 12 & SSR15203 & AGTGACCTGAGGTTGCTGCT & AACGTTGTCCATCCAAATGC & 179 \\
\hline 13 & SSR28327 & TGTTTTTATGTGAAATGGGGC & CGCATCCCTACCCATTTTTA & 203 \\
\hline 14 & SSR30478 & AATTCCCACCACGCAATATC & AAATTACTTTTAAAACACAACCCTTT & 194 \\
\hline 15 & SSR17459 & TTGCCTTCCCTCATATTTGC & TGGTGGGTATTTGTGGTAGGA & 202 \\
\hline 16 & SSR04454 & GGAAAGTGTTGTGTTGCTCTTG & GATCCATTTGATGCATTGCT & 218 \\
\hline 17 & SSR07747 & GATGCACTGTTGGGATTCAA & TTTTTGCCAATTCACAGAGAT & 207 \\
\hline 18 & SSR02460 & CTCAGAAACCCTTCCACCAA & CTGTACCGCGAGGACAGTTT & 160 \\
\hline 19 & SSR06632 & TCAGATGTTGATTGGCTCTCA & AGGGCCAACATTAAAGGGTC & 206 \\
\hline 20 & SSR21936 & TTGGTTGGAAAAAGGAAGGTT & GGGCAGAGGCTTTTTCAATA & 219 \\
\hline 21 & SSR23856 & GAAACGAACAGATGATGGGAA & TTGCTATAGATTCCTTCTCGGTC & 192 \\
\hline 22 & SSR12833 & TCCCGACCTCTTCACGTAAC & GGAAGGCTCATACAGTGGGA & 130 \\
\hline 23 & SSR15316 & TCCAATTTTCTGGCGAAGAC & CAACCGAAACAACGTCTCCT & 189 \\
\hline 24 & SSR02906 & GAAAAGTGCACTCGGTCCAT & CGCATAAAATCCTCCACGTT & 189 \\
\hline 25 & SSR13251 & GGTCAATCCAAAAGAGAAAGCA & ATCAACACCATTGACGACCA & 162 \\
\hline 26 & SSR03147 & GCAAAGCTTTAAGGTTGTTTTTG & GCAAAATGATGTGTGCTTTACC & 220 \\
\hline 27 & SSR12944 & AAGTTTATATTACAGTTGCAACAACCA & TGCACATGTTTAATGGTCCAA & 193 \\
\hline 28 & SSR15606 & GTGGATCCATGGGGATACTG & СССССАСТТСТСТСТССТСТ & 218 \\
\hline 29 & SSR20599 & CATGGTAACTGGTTAGCTCATTTG & TTTATATGGTGTGAATTGAATTTTA & 216 \\
\hline 30 & SSR20218 & CTGGTGGGTTTTCTGAAACG & TCGCCCACGTCCTCTATATC & 210 \\
\hline 31 & SSR21115 & GCAGCAGTCACCCAACCTAT & CACTGTGAACATATGGGAAGGA & 179 \\
\hline 32 & SSR19755 & TATCAGCGAGGGAAGGAAGA & TAATTGCTGCATCGAAGACG & 215 \\
\hline 33 & SSR16683 & TATTCTCATCGGAAAACGCC & TTTGCCCTACTACCCCTCCT & 135 \\
\hline 34 & SSR12510 & TCCTGTAAGCAATCTCCGGT & GGTGGCGACGATATGTCTTT & 178 \\
\hline 35 & SSR07477 & CGTTTCATTCATTGCTGCAC & GCCATCACTAACTGACGCCT & 193 \\
\hline 36 & SSR20704 & ATTGGCCGACCTTATCCTCT & GCCCAGATTTGGTCATTTCTT & 159 \\
\hline 37 & SSR03150 & TTGATTGAATGAATGGTTTGGA & GCСТCТССТTTTCСТCAАCC & 193 \\
\hline 38 & SSR19755 & TATCAGCGAGGGAAGGAAGA & TCAAAATTGATTGGTAAGAAGAAGC & 215 \\
\hline
\end{tabular}

SSR marker Sl. No. 1-5 from melon genome and 6-38 from cucumber genome

ClustalW software (http://www.genome.jp/tools/clustalw/) to detect any sequence variation.

Statistical analysis
Analysis of variance on disease score ratings was done using Minitab18 statistical software (State College, Pennsylvania, USA). Mean disease scores were compared after Tukey's pairwise comparisons. 
Table 3 Foliar disease indices for melon (Cucumismelo L) Genotypes in response to D. bryonae inoculation from growth chamber screening

\begin{tabular}{|c|c|c|c|}
\hline S1. No. & Genotype & Horticultural group & Leaf disease rating \\
\hline 1 & PI482398 & Melo & $1.0 \mathrm{~h}$ \\
\hline 2 & PI482399 & Melo & $1.0 \mathrm{~h}$ \\
\hline 3 & Cornell ZPPM 339 (ZM) & Melo & 3.9 abcdef \\
\hline 4 & Honeydew Greenflesh (HD) & Melo & $4.8 \mathrm{a}$ \\
\hline 5 & PI140471 & Melo & $1.0 \mathrm{~h}$ \\
\hline 6 & PI157082 & Melo & 3.6 abcdef \\
\hline 7 & PI136170 & Melo & $1.0 \mathrm{~h}$ \\
\hline 8 & PI420145 & Melo & $1.0 \mathrm{~h}$ \\
\hline 9 & MR1 & Melo & $4.4 \mathrm{abc}$ \\
\hline 10 & PMR5 & Melo & 3.8 abcdef \\
\hline 11 & PMR45 & Melo & 3.7 abcdef \\
\hline 12 & WMR29 & Melo & 3.7 abcdef \\
\hline 13 & Edisto47 & Melo & 3.6 abcdef \\
\hline 14 & PI414723 & Melo & 4.0 abcde \\
\hline 15 & PI124112 & Melo & $4.6 \mathrm{ab}$ \\
\hline 16 & SCNU1154 & Melo & 3.6 abcde \\
\hline 17 & Charantais & Melo & $2.6 \mathrm{defg}$ \\
\hline 18 & Ananas & Melo & 2.9 cdef \\
\hline 19 & Alpeon & Melo & 4.1 abcde \\
\hline 20 & Dakkijeogyuk & Melo & 3.4 abcdef \\
\hline 21 & Earls Red & Melo & 2.7 defg \\
\hline 22 & Earls top one & Melo & 3.5 abcdef \\
\hline 23 & Ipchumdaegil & Melo & 2.3 abcdef \\
\hline 24 & Captain & Melo & 3.3 abcdef \\
\hline 25 & Darle Spring \& Fall & Melo & 3.2 bcdef \\
\hline 26 & Asia Summer & Melo & 3.5 abcdef \\
\hline 27 & Raina & Melo & 3.9 abcdef \\
\hline 28 & Pestar & Melo & 3.7 abcdef \\
\hline 29 & Earls Focus & Melo & 2.9 cdef \\
\hline 30 & Earls Grand Prix & Melo & 4.0 abcde \\
\hline 31 & JeonnamMelli & Melo & 3.1 cdef \\
\hline 32 & Sweet Lady & Melo & $2.6 \mathrm{defg}$ \\
\hline 33 & Earls Elite & Melo & 3.7 defg \\
\hline 34 & Earls Taitan & Melo & 3.2 bcdef \\
\hline 35 & Kings Daebak & Melo & 3.5 abcdef \\
\hline 36 & Earls Mountain PMR & Melo & 3.9 abcdef \\
\hline 37 & Kingdom & Melo & 3.2 bcdef \\
\hline 38 & Earls Grand & Melo & 3.0 cdef \\
\hline 39 & SS-402 & Melo & $4.1 \mathrm{abcd}$ \\
\hline 40 & Muskmelon SS Anup & Melo & 3.7 abcdef \\
\hline 41 & Asulan PMR & Melo & 3.6 abcdef \\
\hline 42 & Ropey King & Melo & 3.3 abcdef \\
\hline 43 & Napoyon & Melo & 3.3 abcdef \\
\hline 44 & Baldo & Melo & 3.1 bcdef \\
\hline 45 & VCR-601 & Melo & $2.8 \mathrm{def}$ \\
\hline 46 & Earls ok & Melo & $2.7 \mathrm{defg}$ \\
\hline 47 & White Honey & Melo & 3.2 bcdef \\
\hline 48 & Giant Iryesaback & Melo & 2.6 defg \\
\hline 49 & Jochun 26 & Melo & 3.5 abcdef \\
\hline 50 & Valencia Early-rochet & Melo & $2.5 \mathrm{efgh}$ \\
\hline 51 & Asia Papaya & Melo & $1.0 \mathrm{~h}$ \\
\hline 52 & Eunpa 3 & Melo & 3.4 abcdef \\
\hline 53 & ME4759 & Melo & $2.7 \mathrm{defg}$ \\
\hline
\end{tabular}


Table 3 Foliar disease indices for melon (Cucumismelo L) Genotypes in response to D. bryonae inoculation from growth chamber screening (Continued)

\begin{tabular}{clcc}
\hline Sl. No. & \multicolumn{1}{c}{ Genotype } & Horticultural group & Leaf disease rating \\
\hline 54 & Eunpa fall \& Winter melon & Melo & $3.0 \mathrm{cdef}$ \\
55 & Happiness & Melo & $3.0 \mathrm{cdef}$ \\
56 & Sunflower & Melo & $2.6 \mathrm{defg}$ \\
57 & Vivadi & Melo & $2.6 \mathrm{fgh}$ \\
58 & Snow White Melon & Melo & $2.4 \mathrm{defg}$ \\
59 & Supra & Melo & $1.0 \mathrm{~h}$ \\
60 & Chungja & Melo & $2.5 \mathrm{efgh}$ \\
Minimum & & & 1.0 \\
Maximum & & & 4.8 \\
CV (\%) & & & 0.21 \\
\hline
\end{tabular}

Melon lines (1-16) and melon commercial cultivars (17-60)

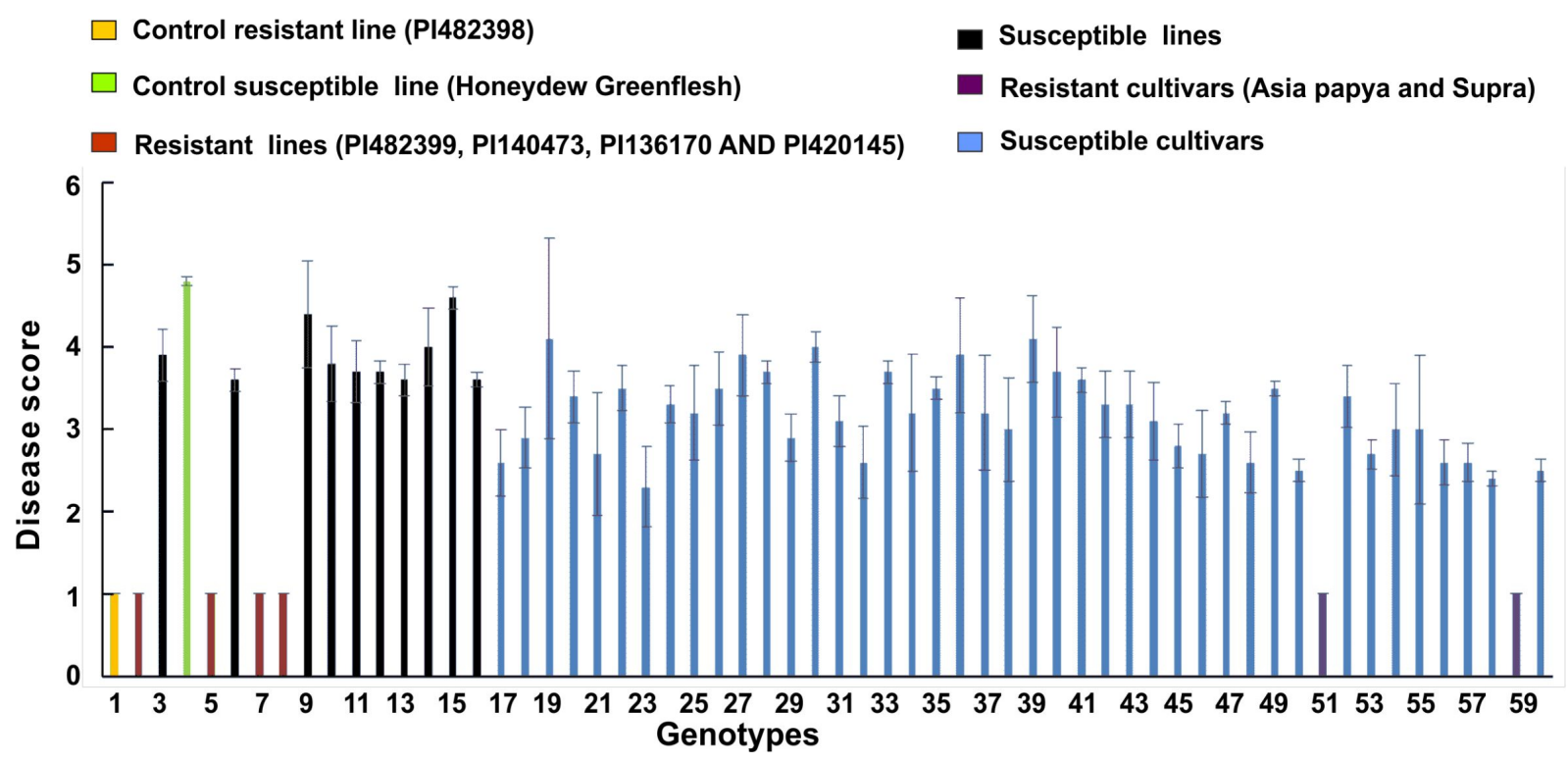

Fig. 2 The disease score of 60 melon genotypes under Didymella bryoniae infection

\section{Results}

Screening of melon lines against $D$. bryoniae

We screened a total of 60 genotypes of melon including resistant and susceptible control against $D$. bryoniae of which 16 were lines and 44 cultivars. Most of the lines were susceptible except 'PI482399', 'PI140471', 'PI136170' and 'PI420145', those exhibited high level of resistance as like as control resistant melon line 'PI48239' 8 with a disease rating of 1.0 (Table 3 and Figure S1). Remaining lines viz. 'Cornell ZPPM 339', 'PI157082', 'MR1', 'PMR5', 'PMR45', 'WMR29', 'Edisto47', 'PI414723', 'PI124112' and 'SCNU1154' showed a similar disease reaction (susceptible) to 'Honeydew Greenflesh', a control susceptible line (Table 3 and Fig. 2). Large differences were observed between the most resistant and susceptible lines (Fig. 2). Among these lines, high level of susceptibility was found in control line 'Honeydew Greenflesh' with disease rating 4.8 which was followed by 'PI124112' (4.6), 'MR1' (4.4), 'PI414723' (4.0), 'Cornell ZPPM 339' (3.9), 'PMR5' (3.8), 'PMR45' (3.7), 'WMR29' (3.7), 'PI157082' (3.6) and 'SCNU1154' (3.6) (Table 3 and Fig. 2).

Screening of Korean melon commercial cultivars against D. bryoniae

Most of the commercial cultivar showed susceptibility in the disease reaction in response of $D$. bryoniae except 'Asia Papaya' and 'Supra' (Fig. S1). 'Asia Papaya' and 'Supra' were found to be highly resistant as like as control resistant line 'PI482398' with disease score rating 1.0 (Table 3 and Fig. 2). In contrast, 'Alpeon' and 'SS-402' were highly susceptible with rating 4.1 and which was near to control susceptible line Honeydew Greenflesh (Table 3 and Fig. 2). 
Screening of melon genotypes by SSR markers

We analyzed a total of 38 previously reported simple sequence repeat (SSR) markers flanking to the resistant genes located in chromosome 1 in melon (Liu et al. 2009), and 4 and 6 in cucumber (Wang et al. 2012 and Ren et al. 2009) (Fig. 3). Twenty SSR markers were shown to be amplified from 12 melon lines, of these eleven were polymorphic between resistant and susceptible line (Fig. 4).

Genotyping of sixteen melon lines

Twenty amplified SSR markers were further used for
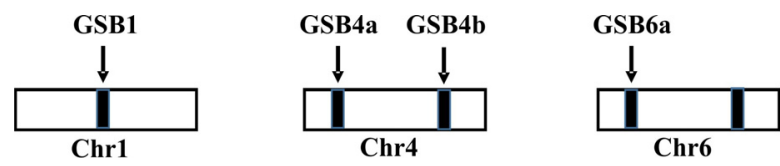

Fig. 3 The map shows the position of SSR markers linked to gummy stem blight resistance in melon and cucumber (Based on Liu et al., 2009 and Lou et al., 2013). Chr1 belongs to melon genome, $\mathrm{Chr} 4$, and $\mathrm{Chr} 6$ from cucumber genome

genotyping 16 melon lines. The result showed that only nine SSR markers were found to be polymorphic (Fig. 5). Among the nine polymorphic markers, 'CMCT505', which was linked to Gsb1 perfectly, grouped resistant and susceptible lines as like as phenotypic data (Table S1). In
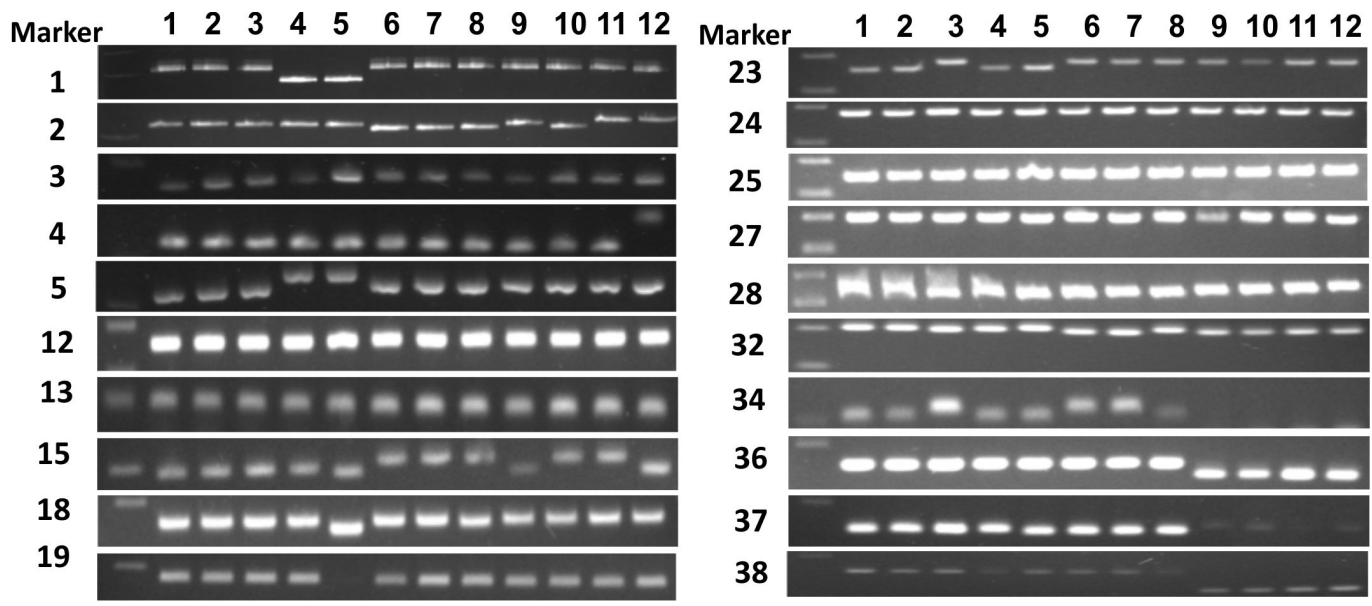

Fig. 4 Banding profile of 20 amplified SSR markers where number in the left and upper side of the gel indicating markers and genotypes, respectively

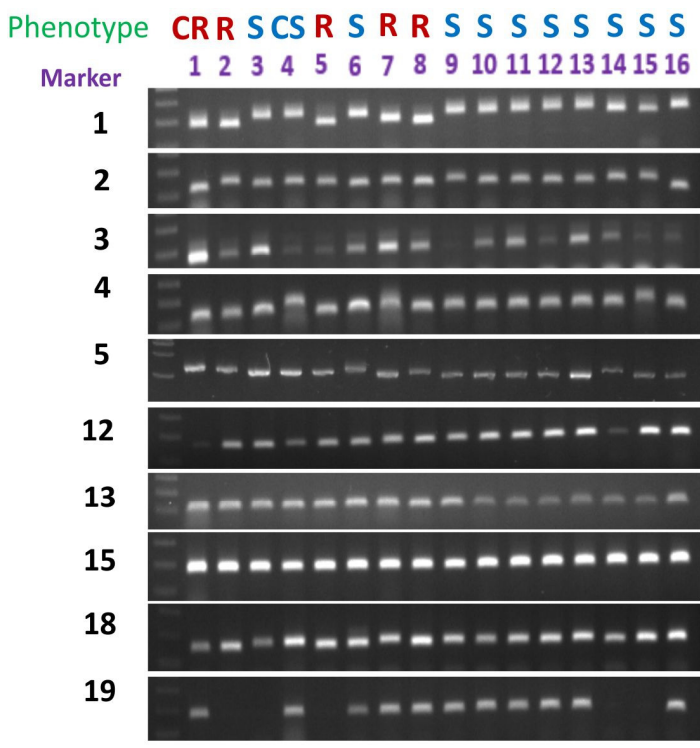

CRR SCSR S R R S S S S S S

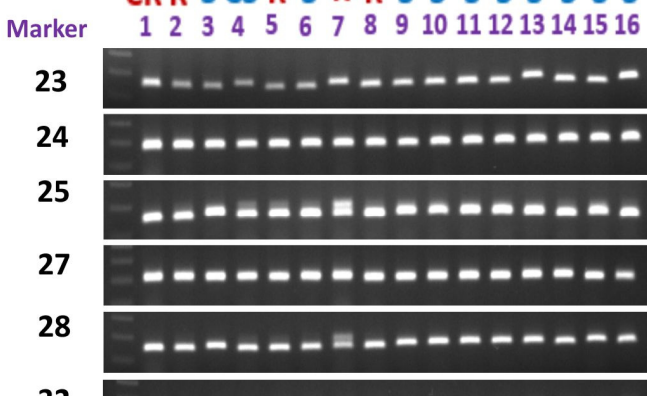

32

34

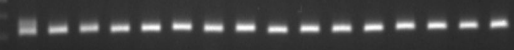

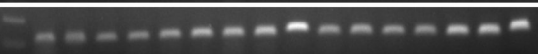

36

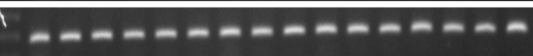

37

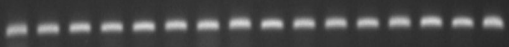

38

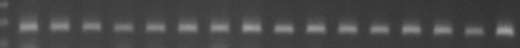

Fig. 5 PCR product for molecular screening of 16 melon lines with 20 amplified SSR markers linked to Gummy Stem Blight and electrophoresed in a 1.5\% agarose gel. L: 100-bp ladder. Number in the left and upper side of the gel indicating markers and genotypes, respectively. CR indicates control resistant line PI482398 and CS indicates control susceptible line Honeydew Greenflesh. $\mathrm{R}$ and $\mathrm{S}$ indicates resistant and susceptible lines, respectively 


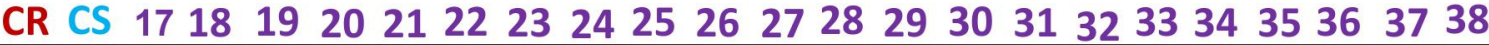

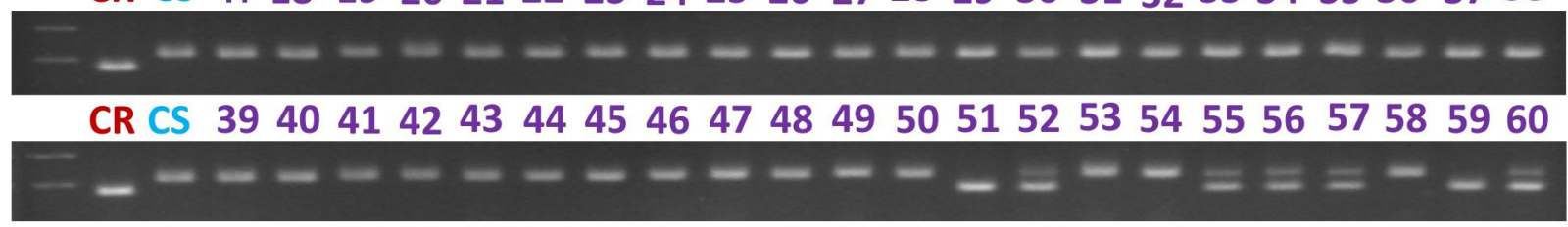

Fig. 6 PCR product for molecular screening of 44 melon commercial cultivars with SSR marker CMCT505 linked to Gummy Stem Blight and electrophoresed in a 1.5\% agarose gel. L: 100-bp ladder. CR and CS indicate control resistant (PI482398) and control susceptible (Honeydew Greenflesh) lines, respectively

addition, the markers $2,4,5,18,23,25,28$ and 34 showed $68.8 \%, 43.8 \%, 25.0 \%, 68.8 \%, 37.5 \%, 75.0 \%, 68.8 \%$ and $50.0 \%$ adaptability, respectively.

Genotyping melon commercial cultivars

Forty-four melon commercial cultivars were also screened by using the polymorphic SSR marker 'CMCT505'. Among 44 cultivars, two cultivars like 'Asia Papaya' and 'Supra' produced identical amplicons as resistant line 'PI482398' (Fig. 6 and Table S2).

Sequencing and comparison of marker amplicons

Cloning and sequencing identified notable variations in the nucleotide sequences between resistant and susceptible lines (Fig. S2). These variations include insertion/deletion (InDel) and single nucleotide polymorphism (SNP) between resistant and susceptible lines and cultivars. The sequence similarity of polymorphic resistant and susceptible lines and cultivars were accounted from 81.4 to $98.3 \%$ (Table S3).

\section{Discussion}

The rate of development in any breeding program can intensely be increased by a reliable screening test that exposes clear differences among individuals or progenies (Abad and Wehner, 1992). In this study, melon leaves were inoculated with $D$. bryoniae to evaluate GSB resistance. Information on the genetics of resistance to the GSB in most melon cultigens are not well elucidated yet (Pitrat et al. 1998). Two genetic systems have been proposed for GSB resistance including monogenic dominant and monogenic recessive (Prasad and Norton, 1967; Frantz and Jahn, 2004).

GSB resistant melon genotypes are essential for further advancement of the melon breeding program as this disease causes serious economic losses. In the present study, we reported some melon lines with a high level of resistance, namely 'PI482399', 'PI140471', 'PI136170' and 'PI420145'.
Similar results were reported by Zhang et al. (1997). Nonetheless, they reported 'PI140471' as moderately resistant line. Moreover, we identified 'PI157082' as a susceptible line which was previously reported as resistant line by Zhang et al. (1997) and Frantz and Jahn (2004) (Table 3 and Fig. 2). In addition, Joseph et al. (2007) reported 'PI482399' as a susceptible but we found as highly resistant with disease score rating 1.0. Furthermore, Sakata et al. (2000) reported 'PI140471' as susceptible against a Japanese isolate of $D$. bryoniae while we found it as highly resistant (Table 3 and Fig. 2). These observed disparities might explain isolate-specific and isolate $\times$ environment-specific resistance response of melon genotypes (Song et al. 2004). Accordingly, the variations of resistance to GSB between the present study and previous report reveals that there might be differences between USA, Chinese, Japanese and Korean D. bryoniae isolates (Table S4). Therefore, further investigation on $D$. bryoniae race identifications is crucial. We also reported two new melon resistant commercial cultivars, including 'Asia Papaya' and 'Supra' (Table 3 and Fig. 2).

Prasad and Norton (1967) reported that disease resistance is due to presence of resistant gene but its expression must be dependent on genetic background. On the other hand, due to environmental variations, only phenotypic selections are not always been effective as well as sensitive to environment. Therefore, identification of marker linked to the disease is an indispensable step towards both marker assisted selection (MAS) and map based cloning (Wang and Roberts, 2006). Keeping these in mind, we screened our genotypes by previously reported SSR markers (Liu et al. 2009). The polymorphism detected by the marker 'CMCT505', 'SSR02460' and 'SSR13251' revealed that GSB resistant gene might be present in resistant lines and cultivars. Among these three markers, since Gsb1 in melon chromosome 1 perfectly separated resistant and susceptible melon genotypes which were confirmed by bioassay screening, therefore, it could be speculated that Gsb1 resistant locus might be existed in Korean resistant melon cultivars. The sequence variations in the flanking SSR markers between 
resistant and susceptible in melon lines and cultivars suggesting that mutation might be occurred during evolution.

Our marker based screening speculates that resistance observed in some selected melon genotypes might be associated with presence of Gsb-1 resistance locus. However, this speculation is a subject of molecular mapping and detection of resistance loci and resistance genes in our melon genotypes.

\section{Acknowledgments}

This study was financially supported by the Golden Seed Project (Center for Horticultural Seed Development, Grant no. 213007-05-2-CG100) of the Ministry of Agriculture, Food and Rural affairs in the Republic of Korea (MAFRA). We thank to Plant Breeding and Genetics Section, School of Integrative Plant Science, Cornell University, USA and USDA, ARS, USA and Daeyeon Breeding, Republic Korea for providing seeds of melon germplasm. We are thankful to Prof. Dr. Molly Jahn, Department of Agronomy, the Nelson Institute, and the Global Health Institute, University of Wisconsin-Madison, USA for her cooperation for collecting melon germplasm. We also thank Han, Kyung Sook, National Institute of Horticultural and Herbal Science (NIHHS), Republic of Korea for providing D. bryoniae isolate.

\section{References}

Abad ZH, Wehner TC (1992) Development of Seedling test for resistance to gummy stem blight in cucumber. Cucurbit Genetics. Cooperative Report 15:23-27

Crosby KM., Miller ME, Wolff DW (2002) Screening plant introductions of Cucumis melo for resistance to Monosporascus cannonballus, In: Maynard D.N. (ed.). Cucubitaceae 2002, American Society of Horticultural Science Press, Alexandria, Va. p. 188-191

Frantz JD, Jahn MM (2004) Five independent loci each control monogenic resistance to gummy stem blight in melon (Cucumis melo L.). Theoretical and Applied Genetics 108: 1033-1038

Gusmini G, Wehner TC (2002) Correlation of ratings for resistance to gummy stem blight in watermelon. In: D.N. Maynard (ed.). American Society of Horticultural Science Press, Alexandria, Va. p. 199-205

Joseph N, Zhou, WXH, Li, Zhang, YB, Chen J F (2007) Resistance to Gummy Stem Blight inMelon (Cucumis melo L.) Germplasm and Inheritance of Resistance from Plant Introductions 157076, 420145, and 323498. Horticultural Science 42:215-221

Joseph N, Zhou, WXH, Chen, JF (2009) Identification of amplified Fragment Length Polymorphism Markers Linked to Gummy Stem Blight (Didymella bryoniae) Resistance in Melon
(Cucumis melo L.) PI 420145. Horticulture Science 44:32-34 Keinath AP, Farnham, FW, Zitter TA (1995) Morphological, pathological, and genetic differentiation of Didymella bryoniae and Phoma spp. Isolated from cucurbits. Phytopathology 85:364-369

Liu WR, Hing ZY, Hui ZX, Feng CJ (2009) SSR Marker Linked to Gummy Stem Blight Resistance Gene Gsb- 1 in Melon and Its Allelism with Resistance Gene from PI420145 Nanjing Agricultural University Journal 5:1-4

Lv D, Cuevas H, Yang Li, Garcia MJ, Zalapa J, Staub J, Luan F, Reddy U, He, X., Gong Z, Weng Y (2012) Syntenic relationships between cucumber (Cucumis sativus L.) and melon (Cucumis melo L.) chromosomes as revealed by comparative genetic mapping. Molecular Biology Genomics 12:396

Li Y, Wen C, Weng Y (2013) Finemapping of the pleiotropic locus $\mathrm{B}$ for black spine and orange mature fruit color in cucumber identifies a $50 \mathrm{~kb}$ region containing a R2R3-MYB transcription factor. Theoretical and Applied Genetics 126:2187-2196

McGrath DJ, Vawdrey L, Walker O (1993) Resistance to gummy stem blight in muskmelon. Horticultural Science 28:930-931

Norton JD, Cosper RD, Smith DA, Rymal K S (1985) AuroraAhigh quality disease resistant cantaloupe. Alburn University Alabama Agricultural Experiment Station 278

Norton JD, Cosper RD (1989) Gummy stem blight resistant muskmelon breeding line. Horticultural Science 24:709-711

Prasad k, Norton J D (1967) Resistance of Mycosphaerella cytrullina in muskmelon. Proceedings for the American Society for Horticultural Science 91:396-400

Pitrat M, Dogimont C, Bardin M (1998) Resistance to fungal diseases of foliage in melon. American Society of Horticultural Science 98:167-173

Ren Y, Zhonghua Z, Jinhua L, Jack ES, Yonghua H, Zhouchao C, Xuefeng L, Hingyuan L, Han M, Houxiang K, Bingyan X, Xianfang G, Xiaowu W, Yongchen D, Weiwei J, Sanwen H (2009) An Integrated Genetic and Cytogenetic Map of the Cucumber Genome. Plos One 4, e5797

StAmand PC, Wehner TC (1991) Crop lossto 14 diseases of cucumber in North Carolina from 1983 to 1988. Cucurbit Genetics. Cooperative Report 14:15-17

StAmand PC, Wehner TC (1995) Greenhouse detached-leaf, and field testing methods to determine cucumber resistance to gummy stem blight. American Society of Horticultural Science 120:673-680

Sitterly RW, Keinath AP (1996) Gummy stem blight. In: Zitter TA,Hopkins DL, Thomas C (eds) Compendium of cucurbit diseases. American Phytopathology Society, APS Press 27-28

Sakata Y, Wako T, Sugiyama M, Morishita M (2000) Screening melons for resistance to gummy stem blight. Acta Horticulturae 510:171-177

Song R, Gusmini G, and Wehner TC (2004) Asummary of eleven preliminary studies of greenhouse and field testing methods for resistance to gummy stem blight in melon. Progress in Cucurbit Genetics and Breeding Research 301-305

Tullu A, Bachwaldt L, Warkentin T, Taran B, Vandenberg A (2002) Genetics of resistance to anthracnose and identification 
of AFLP and RAPD markers linked to the resistance gene in PI 320937 germplasm of lentil (Lens culinaris Medikus). Theoretical and Applied Genetics 106:428-434

Wako T, Sakata Y, Sugiyama Ohara, M, Ishiuji TD, Kojima A, Nishimura S (2002) Identification of melon accessions resistant to gummy stem blight and genetic analysis of the resistance using an efficient technique for seedling test. Acta Horticulturae 588:161-164

Wang CL, Roberts PA (2006) Developmentof AFLP and derived CAPS markers for rootknot nematode resistance in cotton. Euphytica 152:185-196

Wang HY, Chuntao Q, lina L, Qunfeng L, Yongbing Z, Hongping Y, Mingzhu WU, Jinfeng C (2012) A SSR Marker linked to Gsb-4 loci Resistance to Gummy Stem Blight in Melon. Acta Horiculturae Sinica 39:574-580

Wolukau JN, Zhou XH, Zhang YB, Chen JF (2007) "Resistance to gummy stem blight in melon (Cucumis melo L.) germplasm and inheritance of resistance from plant introductions 157076 , 420145, and 323498." Horticulture Science 42:215-221

Wolukau JN, Zhou XH, Chen JF (2009) “Identification of amplified fragment length polymorphism markers linked to gummy stem blight (Didymella bryoniae) resistance in melon (Cucumis melo L.) PI 420145." Horticulture Science 44:32-34

Zhang Y, Kyle MM, Anagnostou K, Zitter TA (1997) Screening melon (Cucumis melo) for resistance to gummy stem blight in the greenhouse and field. Horticulturae Science 32:117-121

Zitter TA, Kyle MM (1992) Impact of powdery mildew and gummy stem blight on collapse of pumpkin (Cucurbita pepo L.). Cucurbit Genetics. Cooperative Report 15:93-96

Zhu H, Guo L, Song P, Luan F, Hu J, Sun X, Yung L (2016) "Development of genome-wide SSR markers in melon with their cross-species transferability analysis and utilization in genetic diversity study." Molecular Breeding 36:153 